\title{
An integrated environmental impact analysis of urban land use change: a study in Yungkang, Taiwan
}

\author{
H.-F. Kuo \& K.-W. Tsou \\ Department of Urban Planning, National Cheng-Kung University, \\ Taiwan
}

\begin{abstract}
The change of urban land-use has had an environmental impact. Although there had already been many case studies discussing the impact to the natural environment for urban land-use in the past, most research failed to explain spatial analysis more deeply and to master the spatial characteristic of the environmental impact. In this paper, we developed a systematic approach for the environmental impact analysis in urban areas that integrates spatial statistical analysis and GIS technology. In terms of the impact, we describe four important environmental performance indicators to evaluate the impact of urban land use change more thoroughly on heat island effects, run-off and habitat diversity which have been used from recent studies, and then evaluated and compared the characteristics of environmental impact and spatial pattern of urban land use change. This study provides a procedure of analysis for environmental impact and future spatial planning. The results also indicated that the environmental impact of land use change was gradually reducing when considering the concept of sustainable development.
\end{abstract}

Keywords: urban land use change, environmental impact analysis, Yungkang.

\section{Introduction}

Urban land use change has occurred to satisfy residential requirements and an improvement in public facilities and the quality of life [5], it was performed by the interaction of politics, economy, society, environment, culture and so on, however, this change usually made a direct and serious impact to the natural environment $[6,18]$. From an ecological perspective, the change of land use is 
one of the most disturbing processes since it dramatically alters the natural energy and material cycles of the ecosystems [10], and damage might be irreversible in some regions since saturation points are being reached and ecological systems are not able to absorb all impact. For this reason, understanding and mastering the environmental impact from land use change had already became an important topic in terms of recent land use planning and urban sustainable development.

The impact of land use had a fairly extensive influence and impact to the environment. There were many factors that could impact the natural environment including habitat diversity [7, 19], hydrology and run-off [5, 9, 19], surface temperatures [12, 19], carbon sequestration and storage [19, 21] and nitrogen mineralization [20] in the past researches. For urban environment, the impact of air or noise was discontinuous and difficult to measure, and explained the impact of urban environment from land use change within limits. Oppositely, the impacts of surface temperatures, run-off and habitat diversity were easily affected by local development, and they were the most important indicators to analyze the environmental impact from the change of land use [12, 19]; meanwhile, they reflected the impact of the urban environment more directly and have been used frequently in relation to research about impact analysis.

Although there had already been many case studies discussing the impact to the natural environment for urban land-use in the past, most focused on single environmental index discussion and were difficult to understand the comprehensive impacts. Meanwhile, possibly owing to the lack of more detailed and identical information of land-use change, most research failed to explain the change of the environmental impacts from past to recent. Besides, the results of the environmental impact were usually shown in statistical charts or tables, it was difficult to understand and master the different impact influences and characteristics at the different spatial units in the complex relation of the environmental spaces.

Therefore, in order to understand the spatial impact characteristics of land-use change to heat island effects, run-off and habitat diversity more thoroughly, this study developed a comprehensive study structure based on GIS techniques, and used spatial statistical methods to analyze environmental performance, characteristics and relationship of the space. These four indicators were evaluated in 39 neighbourhoods in Yungkang, which was a rapid growth satellite city with a total population of 200 thousand in Taiwan. This study first surveyed the land-use data in Yungkang and created a relevant geographical information database according to the classification standards of Taiwan Area National Land Use Survey, and then compared 2006 database with the one established in 1994, evaluated and compared the characteristics of environmental impact and spatial pattern of urban land use change.

\section{Discussing the parameters of environmental impact}

In terms of land use change to environmental impact, Hasse and Lathrop [6] addressed five specific critical land resource impacts including: efficiency of 
land utilization, loss of prime farmland, loss of core forest habitat, loss of natural wetlands, and increase of impervious surface. Whitford et al. [19] deemed the change of land use could affect surface temperature, hydrology, carbon storage and sequestration, and biodiversity. Conway and Lathrop [2] were used to measure the impacts of land use change on water demand, urban non-point source pollution, and terrestrial habitat fragmentation. Haase and Nuissl [6] argued that land use change could affect water balance including: sealing rate, surface run-off, groundwater recharge rate, evapo-transpiration rate. Although the impact of land use change to the environment was fairly extensive, research has demonstrated important environmental parameters such as surface temperatures, storm water run-off and the change of habitats $[7,12,19]$. For this reason, this paper adopted heat island effects, run-off, and habitat diversity to discuss the environmental impacts from land use change. The impact and significance of these three parameters are as follows:

\subsection{Heat island effects}

The surface temperature is believed to give a spatially integrated response of all factors, which influence the physiological and physical canopy behavior [17], it means that land use change had a great impact on urban climate. By covering with buildings, roads and other impervious surfaces, urban areas generally have a higher solar radiation absorption, and a greater thermal capacity and conductivity, so that heat is stored during the day and released by night [18]. Therefore, urban areas have a relatively higher temperature compared with suburban areas; it is called heat island effects. This temperature increase can have negative impacts on human comfort and health $[8,12,15]$, and urban ecoenvironment. Climatic considerations should play an important role in urban planning [4], and the surface temperature also became one of important indicators to analyze the change of land use to environmental impact.

\subsection{Run-off}

The change of land use affected the hydrology system and caused pollution in the groundwater [13]. Run-off from urban areas is also increased because the replacement of vegetation by impervious built and paved surfaces leads to less infiltration $[1,12,19]$, so it has the feature that flooding takes place more frequent and severe in the urban areas [3]. Besides, Arnold and Gibbons [1] also argued that using impervious surface coverage as a framework can be a pragmatic and effective way of addressing a host of complex urban environmental issues. Impervious surfaces created by parking lots, road ways and building footprints prevent ground water infiltration, increase stream surges and channel non point source pollution directly into water bodies [6], and it is becoming an important indicator of water quality degradation within a watershed $[1,6]$, that is to say the surface run-off is an indispensable parameter to the analysis of urban environmental impact $[12,19]$. 


\subsection{Habitat diversity}

The change of land use could decrease the urban habitats and reduce the biodiversity in urban areas. But biodiversity was an important indicator for ecoenvironmental quality assessment, so UNCED contracted "Convention on Biological Diversity" to protect the ecological characteristics within urban areas in 1992. However, urban landscape should play an important role in maintaining the biodiversity [14], biodiversity in urban areas is affected by factors such as the overall amount, size and types of green spaces, and the spatial distribution of green spaces [11, 16], and when the scale of urban habitats were more, the more biological varieties should be contained. So habitat diversity was the most important parameter for maintained biodiversity.

\section{Measuring the impact of environment}

Estimation of surface temperatures from aerial or satellite thermal imagery has been frequently used as a tool to assess the climatic situation within urban areas [12]. Although it was more accurate through direct measurement, it was difficult to compare results if there were no measurements made in every period, besides the problem of clouds and dots per inch (dpi), it also cannot be measured to take into account future changes. Therefore, some scholars began to calculate the change of surface temperature by deducible capacity equations $[13,20]$, it could avert various problems when surveying. There was a suitable equation for surface temperature in Taiwan, and this paper adopted this authentic function as follows:

$$
y=32.81+1.79 \times L_{b}+0.16 \times D_{c}-0.19 \times \log D_{s}-0.43 \times W_{d}-0.37 \times \log D_{c}
$$

where $y$ is surface temperature; $L_{b}$ is building coverage ratio; $D_{c}$ is the distance to coast; $D_{s}$ is the distance to train station; $W_{d}$ is the density of aquatic areas.

The dimension of measure run-off; there were three elements that could be considered - run-off coefficient, rainfall strength, and watershed areas. However, the run-off coefficient is relating to impervious surfaces, and rainfall strength is decided by rainfall duration. According to the studies in Taiwan, the percentage of impervious surface in the residential zone is $86 \%$, the business zone is $100 \%$, the industry zone is $92 \%$, the park and fair is $36 \%$, the school is $68 \%$, the government organization is $91 \%$, natural surface is $0 \%$, artificial surface is $100 \%$; and the function of rainstorm strength during 5 years, referred to in equation (3). These equations were established by a physical environmental survey, and were used frequently. The run-off equation is as follows:

$$
\begin{array}{r}
\mathrm{Q}=\mathrm{C} \text { I A } \\
\mathrm{I}=\frac{500}{(t+5)^{0.413}}
\end{array}
$$


where $Q$ is the amount of run-off; $C$ is run-off coefficient; $I$ is the strength of rainfall; $A$ is watershed areas; and $\mathrm{t}$ is rainfall duration.

The habitats are significant to protect creatures, and habitat diversity maintains the existence of biodiversity. In this paper, we classified the types of urban habitat as park and green space, farm belt, protected area, wetland, turf grass, bare ground, and shrubbery according to different land cover, and then we referred to Shannon-Weaver index to calculate habitat diversity, the equation is as follows:

$$
\begin{gathered}
\mathrm{D}=\mathrm{HA} \\
H=-\sum_{k=1}^{n} P_{k} \ln \left(P_{k}\right)
\end{gathered}
$$

where $D$ is the value of habitat diversity; $H$ is Shannon-Weaver index; $P_{k}$ is the proportion of the habitat types; $n$ is the amount of the habitat types; $A$ is the area of habitats.

\section{Study area}

Yungkang is a satellite city in the Southwest of Taiwan, covering an area of $40.8 \mathrm{~km}^{2}$, it was a rapid growth satellite city with a total population of 200 thousand. Figure 1 presents the location of Yungkang in relation to places within Taiwan. In Yungkang, built-up (57.95\%) and agriculture (32.77\%) land were the major land use types in 2006. The relative surface area of built-up land is 2,364 hectare aggregate in southern and central areas. There was an increase rate of $11.42 \%$ of built-up land and a decrease rate of $3.81 \%$ of agriculture land between 1993 and 2006. The increasingly population growth and urban expansion lead to the fragmentation of agriculture land, reduction in biodiversity, and various environment problems.

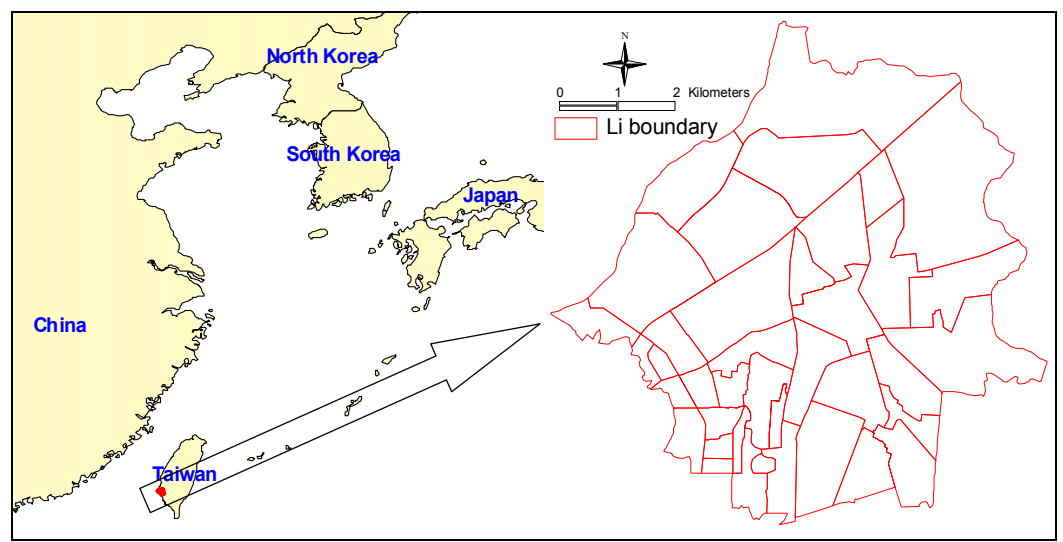

Figure 1: The location of Yungkang. 


\section{Results}

\subsection{Environmental impact}

\subsubsection{Heat island effects}

The heat island effects were simulated between 1993-2006, and the result is shown in Figure 2, the average temperature has increased $0.16^{\circ} \mathrm{C}$. In general, the temperature is higher in the western part than in the east and resulted in different land use types. It has meant that land use change had a great impact on urban climate. On the other hand, there were 17 neighbourhoods where temperature has increased $0.2^{\circ} \mathrm{C}$, within 27 neighbourhoods the temperature increased during a thirteen year period.

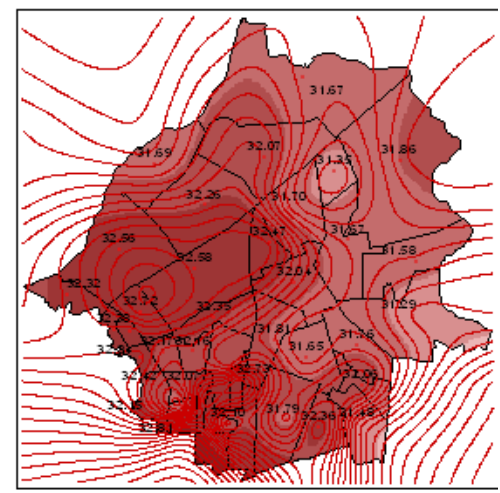

A:1993

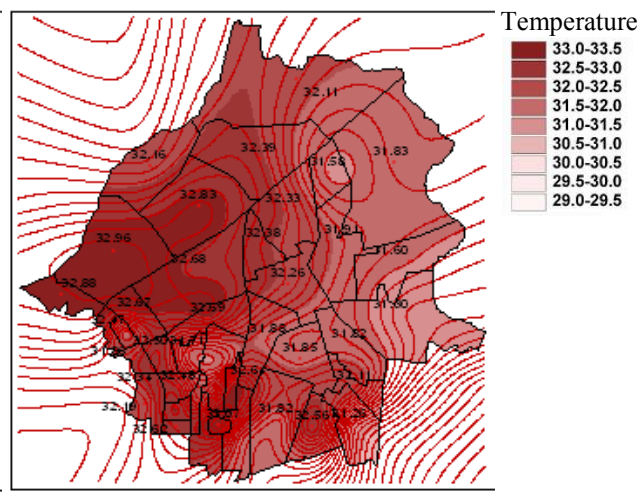

B:2006

Figure 2: Distribution of the heat island effects change within the study area between 1993(A) and 2006(B).

\subsubsection{Run-off}

The percentage of impervious surfaces in Yungkang increased 10.75\% from 1993 to 2006 . We can see the result of the run-off in the Figure 3, the percentage of impervious surfaces was higher and more sprawling. A high percentage of impervious surfaces means the higher strength of urbanization and more development areas. It will bring more run-off and impact the urban environment.

\subsubsection{Habitat diversity}

The result of habitat diversity; the value of the diversity indicator only increased in two neighbourhoods, and the value increases at a further distance from the city centre. That was because of speedy and mass development. The development of urbanization in Yungkang is sprawling, and more and more open space became build-up areas, therefore, the urban habitats will disappearance gradually. 


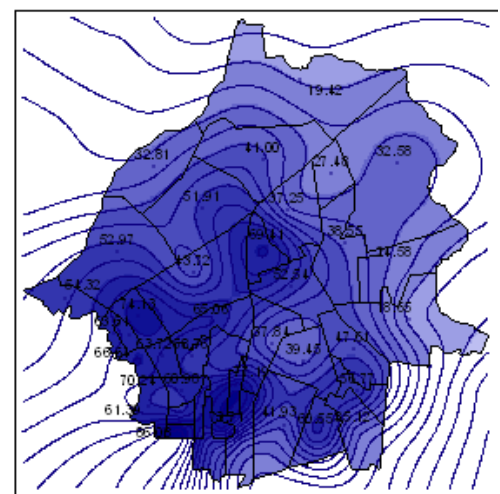

A:1993

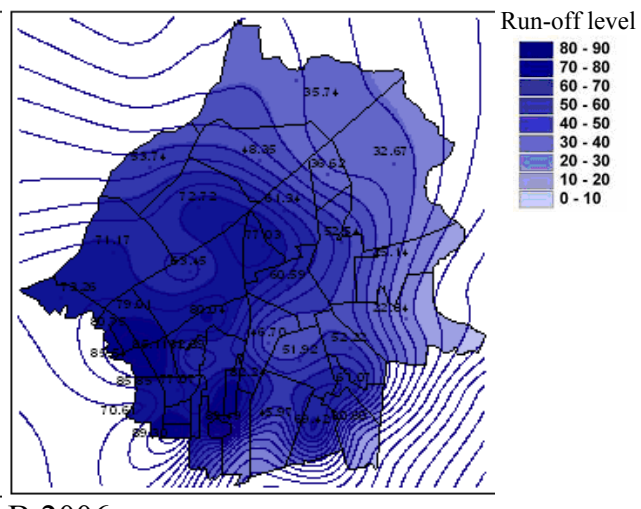

B:2006

Figure 3: Distribution of the run-off chane within the study area between 1993(A) and 2006(B).

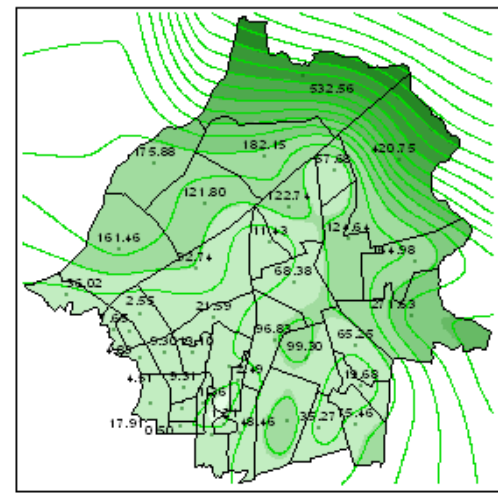

A:1993

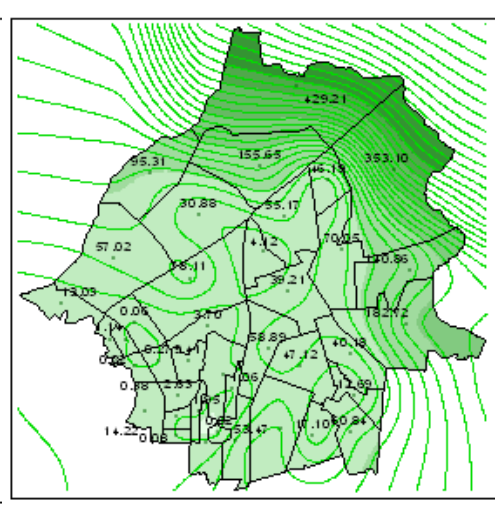

B:2006

Habitat diversity $900-1000$
$800-900$ 700-800 $600-700$ 500-600 400-500 300-400 200-300 $100-200$ 0-100

Figure 4: Distribution of the habitat diversity chane within the study area between 1993(A) and 2006(B).

\subsection{Spatial-temporal change of the environmental impact factors}

In order to compare the relationship of three environmental impact indicators of land use change, factor analysis the class of multivariate statistical methods were carried out. The analysis can first identify the separate dimensions of the structure and then determine the extent to which the variance contributed by each variable is explained by each dimension. In summarizing the change data of environmental impact between 1993 and 2006, the analysis extracts 2 factors with eigenvalues greater than 0.8 , using the principal components and the varimax rotation methods in this paper. The total variance that could be explained by these factors is $87.8 \%$. Factor 1 is named "urbanization factor" and is composed of two indicators: heat island effects (factor loading: 0.86) and run- 
off (factor loading: 0.91). These indicators have positive values and it means that urban expansion and increasing of built-up land is an important factor that affects environmental conditions. Factor 2 is named "diversity factor", composed of one indicator: habitat diversity which has a factor loading of 0.99 .

\subsection{Spatial-temporal change of the spatial cluster}

In order to fully reflect the spatial pattern of the environmental impact condition changes during 1993-2006, the cluster analysis was used to assist the research and clarify the meaning of the data. The K-Means Cluster Analysis procedure was used to identify three clearly defined clusters (Figure 5) across the 39 neighbourhoods of Yungkang. The characteristics and analysis of the clusters are presented below (table 1).

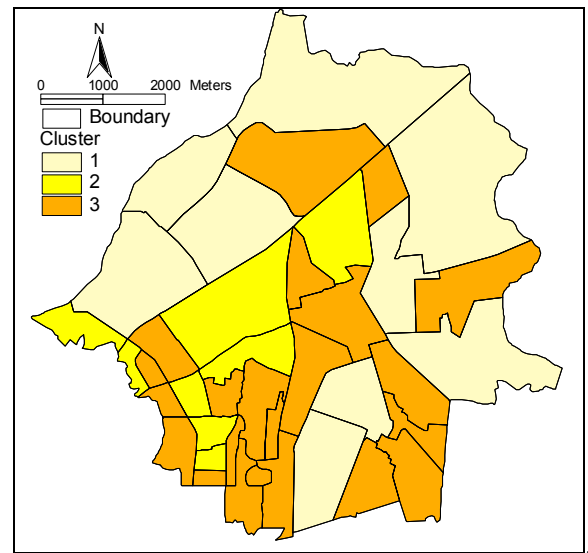

Figure 5: Distribution of spatial cluster of environmental impact change in Yungkang.

Table 1: $\quad$ Each factor's average scores of the three clusters.

\begin{tabular}{|c|c|c|c|}
\hline & Cluster 1 & Cluster 2 & Cluster 3 \\
\hline Factor 1 & 0.0092 & 1.2911 & -0.5572 \\
\hline Factor 2 & -1.5622 & 0.5334 & 0.4409 \\
\hline No. of neighborhood & 9 & 8 & 22 \\
\hline
\end{tabular}

\subsubsection{Cluster 1}

This area includes 9 neighbourhoods, factor 2 is the significant factor, which were gathered in the suburbs of Yungkang. Because the major land use types were composed of agriculture and industrial land and the rate of urban growth was slow, the habitat diversity is worse. The environmental condition is more sustainable than other neighbourhoods. 


\subsubsection{Cluster 2}

Cluster 2 includes eight neighbourhoods which aggregated in the central area, and the land use types were composed of residences, public facilities, highway and industrial land. This area was the first developed part within the study area, various land use resulted in better habitat diversity than others.

\subsubsection{Cluster 3}

There are 22 neighbourhoods belong to emerging area, and might have negative effects on environmental sustainable development. The growth of urban land is developing rapidly with the increasing requirement of residences. Active urban growth management planning will be needed in the future.

\section{Conclusion}

In order to assess the impact on urban sustainability, this paper presents a cohesive assessment procedure of urban land use to investigate the changes in land use and environmental impacts. The results indicate that most neighbourhoods have increasing impacts of three environmental aspects. The main reason should be the increase in built-up land and the disappearing of agriculture land, green space, and urban vacant land. As a result, planners should model the environmental impacts of urban land use development and assess the environmental performance for reviewing the land use plan toward urban sustainable development.

\section{References}

[1] Arnold, C.L., Gibbons, C.J., Impervious land coverage: the emergence of a key environmental indicator. Journal of the American Planning Association, 62(2), pp. 243-259, 1996.

[2] Conway T. M. and Lathrop R. G., Alternative land use regulations and environmental impacts: assessing future land use in an urbanizing watershed. Landscape and Urban Planning, 71, pp. 1-15, 2005.

[3] Douglas, I., The Urban Environment, London: Edward Arnold, 1983.

[4] Eliasson, I., The use of climate knowledge in urban planning. Landscape and Urban Planning, 48, pp. 31-44, 2000.

[5] Haase, D., Nuissl, H., Does urban sprawl drive changes in the water balance and policy? The case of Leipzig (Germany) 1870-2003. Landscape and Urban Planning, In Press, Corrected Proof, Available online 10 July 2006, 2006.

[6] Hasse, J.E., Lathrop, R.G., Land resource impact indicators of urban sprawl. Applied Geography, 23, pp. 159-175, 2003.

[7] Hirzel, A., Hausser, J., Chessel, D., Perrin, N., Ecological-niche factor analysis, how to compute habitat-suitability maps without absence data? Ecology, 83(4), pp. 2027-2036, 2002.

[8] Höppe, P., Different aspects of assessing indoor and outdoor thermal comfort. Energy Buildings, 34, pp. 661-665, 2002. 
[9] Lin, Y.-P., Hong, N.-M., Wu, P.-J., Wu, C.-F., Verburg, P.H., Impacts of land use change scenarios on hydrology and land use patterns in the $\mathrm{Wu}-$ $\mathrm{Tu}$ watershed in Northern Taiwan. Landscape and Urban Planning, In Press, Corrected Proof, Available online 14 August 2006, 2006.

[10] Milesi, C., Elvidgeb, C.D., Nemani, R.R., Running, S.W., Assessing the impact of urban land development on net primary productivity in the southeastern United States. Remote Sensing of Environment, 86, pp. 401410, 2003.

[11] Mörtberg, U., Wallentinus, H.-G., Red-listed forest bird species in an urban environment - assessment of green space corridors. Landscape and Urban Planning, 50, pp. 215-226, 2000.

[12] Pauleit, S., Ennos, R., Golding, Y., Modeling the environmental impacts of urban land use and land cover change - a study in Merseyside, UK. Landscape and Urban Planning, 71, pp. 295-310, 2005.

[13] Randolph, J., Environmental Land Use Planning And Management, Washington: Island Press, 2004.

[14] Sandstrom U.G., Angelstam P., Khakee A., Urban comprehensive planning- identifying barriers for the maintenance of functional habitat networks. Landscape and Urban Planning, 75, pp. 43-57, 2006.

[15] Svensson, M.K., Eliasson, I., Diurnal air temperatures in built-up areas in relation to urban planning. Landscape and Urban Planning, 61, pp. 37-54, 2002.

[16] Thompson, K., Austin, K.C., Smith, R.M., Warren, P.H., Angold, P.G., Gaston, K.J., Urban domestic gardens (I): putting small-scale plant diversity in context. Journal of Vegetation Science, 14, pp. 71-78, 2003.

[17] Wagendorp, T., Gulinck, H., Coppin, P., Muys, B., Land use impact evaluation in life cycle assessment based on ecosystem thermodynamics. Energy, 31, pp. 112-125, 2006.

[18] Weng, Q., A remote sensing-GIS evaluation of urban expansion and its impact on surface temperature in the Zhujiang Delta, China. International Journal of Remote Sensing, 22(10), pp. 1999-2014, 2001.

[19] Whitford V., Handley J. and Ennos R., City form and natural processindicators for the ecological performance of urban areas. Landscape and Urban Planning, 57, pp. 91-103, 2001.

[20] Zeller, V., Bahn, M., Aichner, M., Tappeiner, U., Impact of land-use change on nitrogen mineralization in subalpine grasslands in the Southern Alps. Biology and Fertility of Soils, 31(5), pp. 441-448, 2000.

[21] Zofío, J.L., Prieto, A.M., Environmental efficiency and regulatory standards: the case of $\mathrm{CO} 2$ emissions from OECD industries. Resource and Energy Economics, 23, pp. 63-83, 2001. 